\title{
CA19-9 Level to Serum $\gamma$-Glutamyltransferase as a Potential Prognostic Biomarker in Patients with Pancreatic Head Carcinoma
}

\author{
Shao-Cheng Lyu* \\ Jing Wang* \\ Mengxiu Huang* \\ Han-Xuan Wang \\ Lin Zhou \\ Qiang $\mathrm{He}$ \\ Ren Lang
}

Department of Hepatobiliary and Pancreaticosplenic Surgery, Beijing ChaoYang Hospital, Capital Medical University, Beijing, 100020, People's Republic of China

*These authors contributed equally to this work
Correspondence: Ren Lang Department of Hepatobiliary and Pancreaticosplenic Surgery, Beijing ChaoYang Hospital, Capital Medical University, No. 8 Gongtinan Road,

Chaoyang District, Beijing, 100020,

People's Republic of China

Tel +86-10-85231504

Fax +86-| $0-8523 \mid 503$

Email dr_langren@126.com
Background: The aim of this study was to reduce the influence of biliary obstruction on carbohydrate antigen 19-9 level (CA19-9) by introducing the CA19-9 level to serum $\gamma$ glutamyltransferase (GGT) ratio as an indicator, and ultimately to reveal the correlation between CA19-9/GGT and the prognosis of patients with pancreatic head carcinoma (PHC). Methods: A total of 339 enrolled patients who underwent pancreatoduodenectomy for PHC in Beijing ChaoYang Hospital from January 2010 to December 2019 were analyzed retrospectively. The optimal cut-off value, according to which patients were divided into a lowratio group (Group 1, $\mathrm{n}=179$ ) and a high-ratio group (Group 2, $\mathrm{n}=160$ ), was determined by the ROC curve obtained from preoperative CA19-9/GGT and 1-year survival. Through univariate and multivariate analyses, risk factors for postoperative tumor recurrence and long-term survival were screened out among PHC patients.

Results: The best cut-off value of CA19-9/GGT was 2.07 (area under the curve $=0.567,95 \%$ CI 0.498-0.636). Compared with Group 2, Group 1 had lower CA19-9, and higher GGT, total bilirubin (TB) and lymph-node metastasis rate $(P<0.05)$. The 1-, 2- and 3-year diseasefree survival rates of patients in Groups 1 and 2 were $68.2 \%, 42.5 \%$ and $28.2 \%$, and $42.2 \%$, $19.3 \%$ and $18.3 \%$, respectively $(P=0.000)$, and the 1 -, 2 - and 3 -year overall survival rates were $79.1 \%, 50.7 \%$ and $29.1 \%$, and $56.7 \%, 22.2 \%$ and $17.2 \%$, respectively $(P=0.000)$. Multivariate analysis showed that CA19-9/GGT, portal system invasion and lymph-node metastasis were independent risk factors for postoperative tumor recurrence and long-term survival among patients with PHC.

Conclusion: Compared with CA19-9 level alone, CA19-9/GGT plays a more precise role in the evaluation of postoperative tumor recurrence and the long-term prognosis of PHC patients. The lower the ratio, the better the long-term prognosis. The CA19-9/GGT ratio may prove to be a useful biomarker for identifying PHC patients at high risk of early recurrence and unfavorable prognosis.

Keywords: pancreatic head carcinoma, pancreatoduodenectomy, carbohydrate antigen 19-9, $\gamma$-glutamyltransferase, prognosis

\section{Introduction}

Pancreatic carcinoma represents one of the commonest cancers of the digestive system. On account of its high malignancy and great tendency toward local vascular invasion and distant metastasis, its overall resection rate is less than $20 \%$ and its 5-year survival rate is less than $10 \% .{ }^{1}$ Its morbidity rate is ranked fourteenth while its mortality rate is ranked sixth worldwide, according to the global cancer statistics in $2018 .^{2}$ Currently, radical surgical resection remains the best treatment option for 
pancreatic carcinoma, ${ }^{3}$ thus emphasizing the importance of predicting the long-term prognosis of patients with pancreatic carcinoma before surgery so as to make optimal treatment decisions.

Abnormally elevated carbohydrate antigen 19-9 (CA19-9) levels are seen in patients with malignant cancers, including pancreatic carcinoma, cholangiocarcinoma and gallbladder carcinoma. It has been proven by extensive research that CA19-9 has a close correlation with diagnosis, prognosis and postoperative tumor recurrence in pancreatic carcinoma. ${ }^{4,5}$ However, CA19-9 can not only be found in tumor patients' blood, but also be detected at a low concentration in healthy people, since the epithelium of the pancreas, bile duct, stomach and colon is able to synthesize CA19-9 as well. ${ }^{6,7}$ When biliary obstruction occurs, CA19-9 secreted by biliary epithelial cells cannot be excreted into the intestinal tract, while CA19-9 secreted by pancreatic epithelial cells may reflux back to the bile duct. Besides, biliary inflammation secondary to obstruction stimulates the hyperplasia of biliary epithelial cells, resulting in an increase in blood CA19-9 levels. ${ }^{8}$ Consequently, the sensitivity of CA19-9 as a marker is limited since its elevation can also be seen in some benign biliary obstructive diseases and biliary inflammatory diseases. ${ }^{9}$ For PHC patients, the CA19-9 level can also be affected if biliary obstruction caused by oncothlipsis or bile-duct invasion occurs, reducing its utility in predicting long-term prognosis.

$\gamma$-Glutamyltransferase (GGT), which is distributed widely in the human body and is primarily located on cell membranes, leads to various chronic metabolic disorders as a result of its key role in glutathione metabolism and its roles in pro-oxidation and proinflammatory procedures. ${ }^{10}$ Oxidation stress and inflammation are also pathways implicated in cancer development and progression, implying the close correlation between GGT and tumor occurrence. GGT may also be related to the long-term prognosis of cancers. According to research, ${ }^{11}$ a high level of serum GGT indicates poor long-term prognosis among patients with pancreatic carcinoma.

Our study aims to reduce the influence of biliary obstruction on CA19-9 level by introducing the CA19-9 level to serum GGT ratio as an indicator, and ultimately to reveal the correlation between CA19-9/GGT and the postoperative tumor recurrence and long-term prognosis of PHC patients.

\section{Materials and Methods}

\section{Ethics Approval and Consent to Participate}

The study was conducted in accordance with the Declaration of Helsinki (as revised in 2013) and was approved by the Ethics Committee of Beijing Chaoyang Hospital (No. 2020-D.-309-2). The requirement for participants' informed consent was exempted because of the retrospective study design, and the study design was approved by the appropriate ethics review board.

\section{Patients and Clinicopathologic Factors}

\section{Patient Selection}

Our study retrospectively analyzed the data of PHC patients who underwent surgical treatment in the Department of Hepatobiliary and Pancreaticosplenic Surgery of Beijing ChaoYang Hospital from January 2010 to December 2019, and screened out 339 eligible patients for further analysis according to the inclusion and exclusion criteria (Figure 1). The authors are accountable for all aspects of the work, in ensuring that questions related to the accuracy or integrity of any part of the work are appropriately investigated and resolved.

\section{Inclusion and Exclusion Criteria}

Inclusion criteria: 1) PHC patients underwent pancreatoduodenectomy (PD) from January 2010 to December 2019; 2) no restrictions were imposed on age and gender; 3) preoperative evaluation showed no distant metastasis; 4) patients underwent en bloc resection during surgery; 5) postoperative pathology confirmed the diagnosis of pancreatic ductal adenocarcinoma; and 6) clinical and follow-up information was complete.

Exclusion criteria: 1) unable to resect the tumor during surgery; 2) surgical rule violation; 3) postoperative pathology confirmed tumor histologic types other than conventional pancreatic ductal adenocarcinoma; and/or 4) lost to follow-up after surgery.

\section{General Condition of Patients}

A total of 339 patients met our inclusion criteria, including 192 males and 147 females. The ratio of males to females was $1.3: 1$ and their average age $(\operatorname{mean} \pm \mathrm{SD})$ was $63.0 \pm 10.1$ years. Initial symptoms mainly included abdominal pain $(n=146)$, jaundice $(n=134)$ and atypical gastrointestinal symptoms $(n=19)$, while the rest of the patients showed no symptoms and the disease was not detected until physical examination. A history of diabetes 


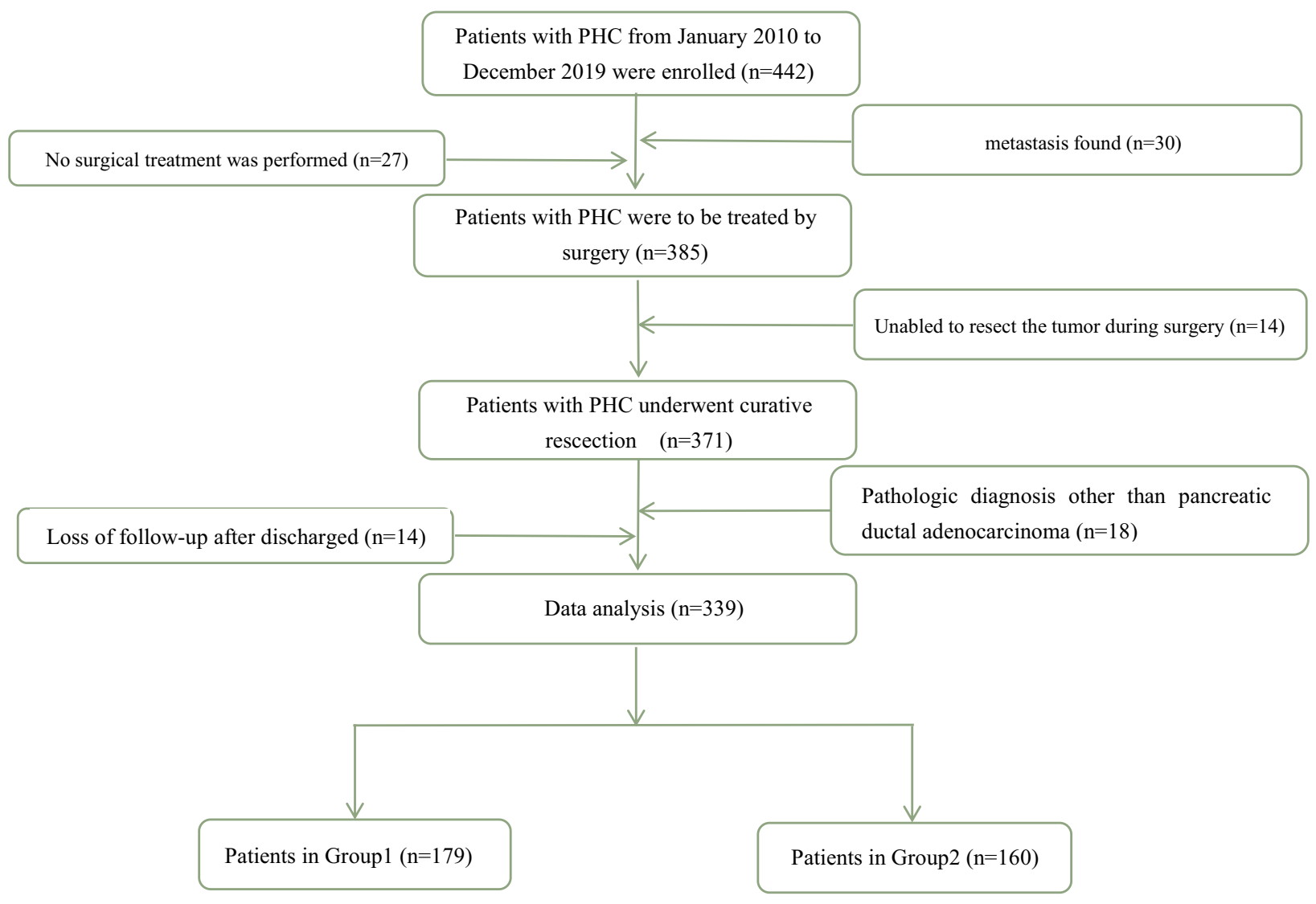

Figure I Screening flowchart.

was noted in 117 patients (34.5\%). Of the 134 patients with jaundice, 56 underwent preoperative jaundice-reducing treatment, including 19 patients who underwent endoscopic retrograde cholangiopancreatography (ERCP) and 37 patients who underwent percutaneous transhepatic biliary drainage (PTBD) treatment.

\section{Patient Grouping and Definition}

The receiver operating characteristics (ROC) curve was obtained based on the ratio of CA19-9/GGT and the 1-year survival rate, from which the optimal cut-off value of CA19-9/GGT was determined to be 2.07 [area under the curve $(\mathrm{AUC})=0.567,95 \%$ CI $0.498-$ $0.636]$. The sensitivity in predicting the 1 -year survival condition of patients was $62.7 \%$, while its specificity was 58.8\% under this circumstance (Figure 2). Patients were divided into two groups, a low-ratio group (Group 1, CA19-9/GGT <2.07, $\mathrm{n}=179$ ) and a highratio group (Group 2, CA19-9/GGT >2.07, $\mathrm{n}=160$ ), according to the optimal cut-off value. The levels of serum CA19-9 and GGT were measured in the last blood sample before surgery. For patients who underwent jaundice reduction treatment, our center examined the levels of serum CA19-9 and GGT on the day of surgery separately.

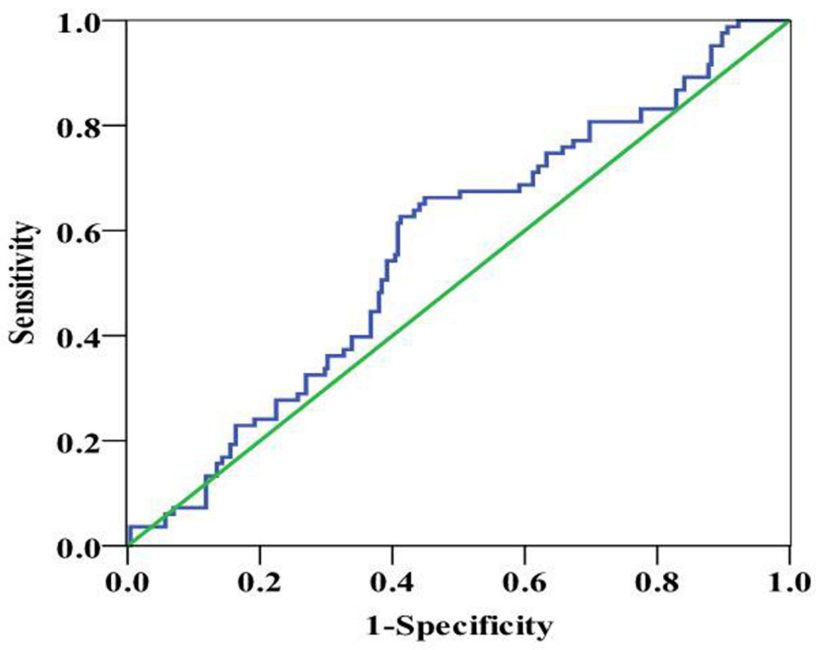

Figure 2 Time-dependent receiver operating characteristics curve. (The AUC of the CAI9-9 to $\gamma$-glutamyltransferase ratio to predict the 1 -year OS is 0.567 .). 


\section{Follow-Up Strategy}

Our follow-up finished in June 2020 and the median follow-up period was 51 months. The perioperative information and postoperative recovery condition of enrolled patients were obtained from medical records and were compared between different groups. We scheduled follow-up for the first and the third months within the first 3 months. Then we arranged follow-up every 3 months within the first 2 years after the operation and every 6 months after 2 years. Tumor recurrence and death of patients indicated the endpoints of follow-up visits. Blood tests (routine blood tests, blood biochemistry, CA19-9), imaging examinations (abdominal enhanced CT, pulmonary CT), follow-up treatments, tumor recurrence and survival conditions were included.

\section{Statistical Analysis}

Measurement data fitting a normal distribution were expressed as mean \pm standard deviation while data fitting a non-normal distribution were expressed as median (interquartile range). The $t$-test was adopted for the normal distribution and the rank-sum test was used for the non-normal distribution when comparing measurement data between the two groups. The chi-squared test was used to compare the counting data between the two groups and Fisher's exact probability method was used when the theoretical frequency was less than 1. Survival curves were calculated using the Kaplan-Meier method and evaluated with the log-rank test. Statistical significance was defined as $P<0.05$ and all data were analyzed by SPSS 24.0 software.

\section{Results}

\section{Perioperative Condition}

The surgery went smoothly for all of the enrolled patients and the tumors were removed successfully, including in 122 patients in whom the tumor was combined with portal system invasion: 85 of these cases underwent allogenic vascular replacement, 25 cases underwent end-to-end anastomosis and the other 12 cases underwent direct suture after wedge resection of the invaded vessels. The intraoperative bleeding volume was $500(400-800) \mathrm{mL}$ and 120 patients $(35.4 \%)$ received a blood transfusion during surgery. The mean operative time was $9.9 \pm 2.9$ hours.

All patients' diagnoses were confirmed by postoperative pathology as pancreatic ductal adenocarcinoma, including 23 cases $(6.8 \%)$ of highly differentiated tumors, 229 cases $(67.6 \%)$ of moderately differentiated tumors and
87 cases $(25.7 \%)$ of poorly differentiated tumors. Lymphnode biopsies were positive in 222 cases $(65.5 \%)$. The mean diameter of tumors was $3.8 \pm 1.7 \mathrm{~cm}$. Radical resection (R0) was achieved in 314 cases (92.6\%); besides, biopsies of the pancreatic incisal margin were positive in nine cases $(2.7 \%)$, biopsies of the pancreatic circumferential margin were positive in nine cases $(2.7 \%)$, biopsies of the pancreatic uncinate process incisal margin were positive in four cases $(1.2 \%)$ and biopsies of the portal sulcus margin were positive in three cases $(0.9 \%)$.

\section{Postoperative Complications}

Postoperative complications occurred in 95 patients, with a morbidity rate of $28.0 \%$, including 29 cases $(8.6 \%)$ of biochemical fistula, eight cases (2.4\%) of level B pancreatic fistula and five cases (1.5\%) of level C pancreatic fistula; abdominal infection occurred in 20 cases $(5.9 \%)$ and delayed gastric emptying (DGE) in 17 (5.0\%); and there were 10 cases $(2.9 \%)$ of abdominal hemorrhage, six $(1.8 \%)$ of biliary fistula, five $(1.5 \%)$ of pulmonary infection, three $(0.9 \%)$ of gastrointestinal hemorrhage, two $(0.6 \%)$ of intestinal fistula, two $(0.6 \%)$ of portal vein thrombosis and one case $(0.3 \%)$ of pulmonary embolism. Three patients died perioperatively owing to a level $\mathrm{C}$ pancreatic fistula complicated by abdominal hemorrhage, and the perioperative mortality was $0.9 \%$. The median postoperative hospital stay was 17 (14-22) days.

\section{Survival Data and Recurrence}

The follow-up period was up to June 2020 , with a median follow-up period of 51 months, during which 191 (56.3\%) of all included patients received postoperative adjuvant chemotherapy for one to eight cycles. The overall median disease-free survival (DFS) time was 15 months and the 1-, 2- and 3-year DFS rates were $56.0 \%, 31.8 \%$ and $23.2 \%$, respectively (Figure $3 \mathrm{~A}$ ). The median overall survival (OS) time was 18 months and the OS rates 1 year, 2 years and 3 years after the operation were $68.6 \%, 37.5 \%$ and $23.3 \%$, respectively (Figure $3 \mathrm{~B}$ ).

\section{Comparison of Perioperative and Long-Term Prognostic Data in Different Groups}

The general condition of patients in the different groups was compared and the results are shown in Table 1, from which it can be found that patients in Group 1 had a lower level of CA19-9 and higher levels of GGT, total bilirubin 


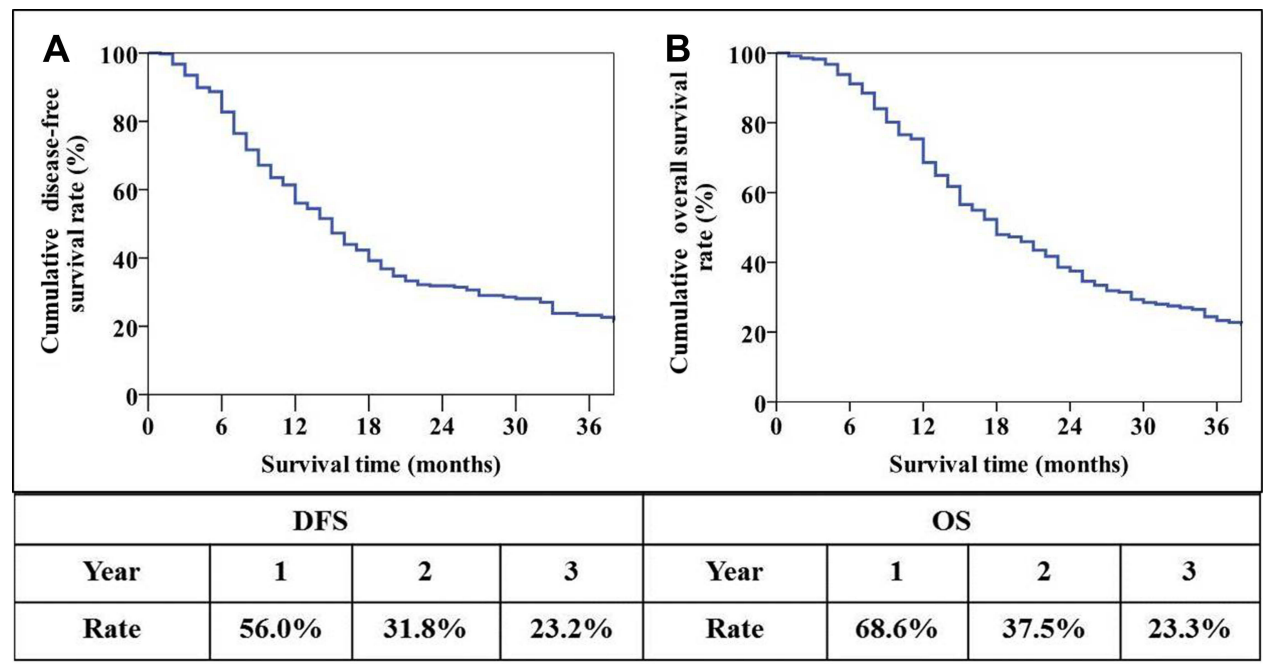

Figure 3 Long-term prognosis of patients with PHC. (A) Overall disease-free survival curve of patients; (B) overall survival curve of patients..

(TB) and lymph-node metastasis rate compared to Group 2 $(P<0.05)$. The comparison of the main postoperative complications within different groups is shown in Table 2, which shows that there were no significant differences in postoperative mortality or the incidence of complications between the two groups $(P>0.05)$.

The median DFS of patients in Groups 1 and 2 was 19 and 11 months, respectively, and the 1-, 2- and 3-year DFS rates were $68.2 \%, 42.5 \%$ and $28.2 \%$, and $42.2 \%, 19.3 \%$ and $18.3 \%$, respectively $(P=0.000)$ (Figure $4 \mathrm{~A})$. The median OS of patients in Groups 1 and 2 was 25 and 14 months, respectively, and the 1-, 2- and 3-year OS rates were $79.1 \%, 50.7 \%$ and $29.1 \%$, and $56.7 \%, 22.2 \%$ and $17.2 \%$, respectively $(P=0.000)$ (Figure $4 \mathrm{~B})$.

\section{Risk Factors for Postoperative Tumor Recurrence in Patients with PHC}

Postoperative tumor recurrence in PHC patients was defined as a dependent variable, while preoperative data, intraoperative data, pathologic data and postoperative data were defined as independent variables for univariate analysis; the results are shown in Table 3. It can be seen that the level of CA19-9, CA19-9/GGT, operative time, intraoperative blood loss, blood transfusion, degree of differentiation, tumor size, lymph-node metastasis and portal system invasion may be risk factors for postoperative tumor recurrence in patients with PHC. Furthermore, we incorporated these variables into a Cox proportional hazard model for multivariate analysis, and the results are detailed in Table 4. It can be seen that CA19-9/GGT
$(\mathrm{RR}=1.397,95 \% \mathrm{CI} 1.054-1.852)$, portal system invasion $(\mathrm{RR}=1.561,95 \% \mathrm{CI} 1.167-2.086)$ and lymph-node metastasis $(R R=2.325,95 \%$ CI 1.711-3.160) were independent risk factors for postoperative tumor recurrence in PHC. Meanwhile, CA19-9/GGT $\leq 2.07$, without portal system invasion or lymph-node metastasis, indicated a lower risk of postoperative tumor recurrence.

\section{Risk Factors for Postoperative Long-Term Survival in Patients with PHC}

Postoperative long-term prognosis was defined as a dependent variable, while preoperative data, intraoperative data, pathologic data and postoperative data were defined as independent variables for univariate analysis, and the results are shown in Table 5 It can be seen that level of CA19-9, CA19-9/GGT, operative time, intraoperative blood loss, blood transfusion, degree of differentiation, tumor size, lymph-node metastasis, portal system invasion and condition of the incisal margins may be risk factors influencing long-term survival in patients with PHC. These 10 indicators were included in the Cox proportional hazard model for multivariate analysis, as detailed in Table 6. It can be seen that CA19-9/GGT (RR=1.526, 95\% CI 1.143-2.038), portal system invasion $(\mathrm{RR}=1.621,95 \%$ CI 1.214 2.166) and lymph-node metastasis ( $\mathrm{RR}=2.389,95 \% \mathrm{CI}$ 1.753-3.256) were independent risk factors influencing postoperative long-term survival in patients with PHC. Patients with CA19-9/GGT $\leq 2.07$, and no portal system 
Table I Demographic and Pathologic Findings in the Two Groups of Patients with PHC

\begin{tabular}{|c|c|c|c|}
\hline Variables & Group I $(n=\mid 79)$ & Group $2(n=160)$ & $P$ \\
\hline Gender (M/F) & $86 / 93$ & $86 / 74$ & 0.294 \\
\hline Age (years), mean \pm SD & $63.5 \pm 9.9$ & $62.5 \pm 10.3$ & 0.372 \\
\hline Diabetes (N/A) & $54 / 125$ & $63 / 97$ & 0.075 \\
\hline $\mathrm{PBD}(\mathrm{N} / \mathrm{A})$ & $35 / 144$ & $21 / 139$ & 0.112 \\
\hline TB $(\mu \mathrm{mol} / \mathrm{L})$ & $80.4(17.6,175.0)$ & $12.3(9.3,40.5)$ & 0.000 \\
\hline CAI9-9 (U/mL) & $59.8(22.4,182.7)$ & $693.1(233.6,2005.2)$ & 0.000 \\
\hline GGT (U/L) & $513(115,960)$ & $28(18,153)$ & 0.000 \\
\hline Intraoperative blood loss ( $\mathrm{mL}$ ) & $500(400,800)$ & $500(400,800)$ & 0.455 \\
\hline Blood transfusion (N/A) & $60 / 119$ & $60 / 100$ & 0.444 \\
\hline Operative time $(h)$, mean \pm SEM & $9.7 \pm 2.6$ & $10.1 \pm 3.2$ & 0.254 \\
\hline Tumor size $(\mathrm{cm})$, mean \pm SD & $3.7 \pm 1.7$ & $4.0 \pm 1.8$ & 0.116 \\
\hline Degree of differentiation (poor/moderate-high) & $48 /|3|$ & $39 / 121$ & 0.608 \\
\hline Portal system invasion (N/A) & $58 / 121$ & $64 / 96$ & 0.146 \\
\hline Neoadjuvant chemotherapy (N/A & $8 / 171$ & $12 / 148$ & 0.237 \\
\hline LN metastasis $( \pm)$ & $99 / 80$ & $123 / 37$ & 0.000 \\
\hline Resection margin (R0/RI) & $166 / 13$ & $148 / 12$ & 0.933 \\
\hline Postoperative chemotherapy (N/A) & $97 / 82$ & $94 / 66$ & 0.398 \\
\hline Chemotherapy period & $2(0,5)$ & $2(0,4)$ & 0.635 \\
\hline
\end{tabular}

Abbreviations: PBD, preoperative biliary drainage; TB, total bilirubin; CAI9-9, carbohydrate antigen 19-9; GGT, $\gamma$-glutamyltransferase; LN, lymph node; R, resection margin.

invasion or lymph-node metastasis are indicated to have a better long-term prognosis.

\section{Discussion}

Early recurrence of PHC after surgical resection is the key reason for its poor long-term prognosis. Indicators including tumor size, degree of differentiation, lymph-node metastasis and vascular invasion have been reported to have a close relationship with postoperative tumor recurrence and long-term prognosis. ${ }^{12,13}$ However, these factors cannot be measured without postoperative pathology, limiting their clinical application value in predicting patients' long-term prognosis before surgery. Thus, preoperative indicators, according to which doctors are able to evaluate the long-term prognosis of patients and make optimal treatment decisions, are badly needed in clinical practice.

CA19-9 remains one of the most valuable serum markers in diagnosing pancreatic carcinoma and predicting

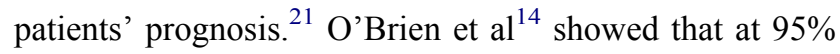
specificity, CA19-9 (>37 U/mL) had a sensitivity of $68 \%$ up to 1 year and $53 \%$ up to 2 years before diagnosis, therefore concluding that CA19-9 can be applied to the early detection and diagnosis of pancreatic carcinoma. Sugiura et al ${ }^{15}$ retrospectively analyzed 154 patients with

Table 2 Morbidity and Mortality in the Two Groups

\begin{tabular}{|l|c|c|c|}
\hline Variables & Group I (n=179) & Group 2 (n=160) & P \\
\hline Postoperative hospital stay (days) & $17(14-24)$ & $17(13-22)$ & 0.298 \\
Perioperative mortality & 2 & 1 & 0.922 \\
Perioperative complications & 51 & 44 & 0.839 \\
Biochemical fistula & 15 & 14 & 0.903 \\
Pancreatic fistula & 5 & 3 & 0.843 \\
Level B & 2 & 3 & 0.899 \\
Level C & 11 & 6 & 0.313 \\
DGE & 11 & 9 & 0.839 \\
Abdominal infection & 6 & 4 & 0.888 \\
Abdominal hemorrhage & & & \\
\hline
\end{tabular}

Abbreviation: DGE, delayed gastric emptying. 

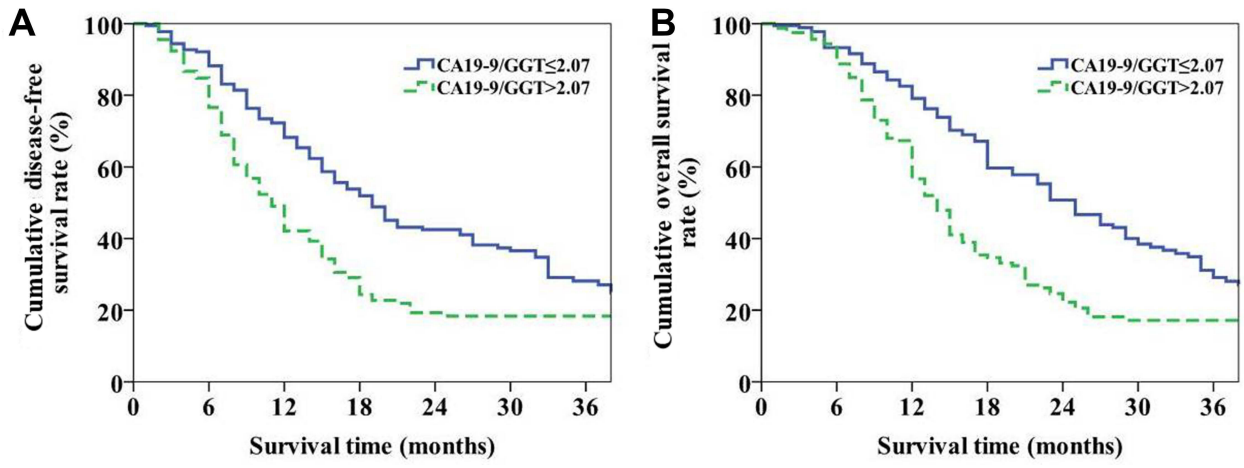

Figure 4 Overall long-term prognosis between the two groups in patients with PHC. (A) Overall disease-free survival curve of the two groups of patients; (B) overall survival curve of the two groups of patients.

pancreatic carcinoma who underwent PD before, finding that preoperative CA19-9 was an independent risk factor influencing the long-term prognosis of patients with pancreatic carcinoma, and patients with a low level of CA19-9 had a significantly longer median survival time compared to those with a high level of CA19-9 (31 vs 16 months). Through a systematic review of the literature, Boeck et al ${ }^{5}$ asserted that CA19-9 was an important serum marker in predicting prognosis and monitoring the disease condition among patients with pancreatic carcinoma, and that a decline in the CA19-9 concentration indicated a positive effect of treatment, to some degree.

Some scholars have also pointed out that despite having a sensitivity of more than $80 \%$ in the diagnosis of pancreatic carcinoma, CA19-9 has a significantly lower accuracy in differentiating benign and malignant disease among patients with obstructive jaundice. ${ }^{16,17}$ Mann et $\mathrm{al}^{18}$ reviewed 164 patients with abnormally elevated CA19-9 levels. Through comparison, they found that the accuracy of CA19-9 in diagnosing malignant tumors was only $48.4 \%$ in patients with jaundice and the level of CA19-9 was proportional to the level of bilirubin. As a result of the particular location of tumor PHC, the tumor may oppress or invade the bile duct gradually as it grows, causing an unmatched increase in the concentration of CA19-9. In our study, up to $79.4 \%$ of patients with a CA19-9 level greater than $37 \mathrm{U} / \mathrm{mL}$ were diagnosed as having pancreatic carcinoma, and their prognosis was significantly worse than for those whose CA19-9 was less than $37 \mathrm{U} /$ $\mathrm{mL}(P=0.025)$. However, multivariate analysis showed that CA19-9 was not an independent risk factor for prognosis. We attributed this phenomenon to the relatively high proportion of patients with biliary obstruction included in our research. Since the bile excretion disorder led to the abnormal increase in the overall concentration of CA19-9, it could not reflect the prognosis of patients authentically.

GGT is a kind of mitochondrial enzyme with sulfhydryl and it has been shown to be a cell-surface glycoprotein, which is widely distributed in substantial organs such as the liver, kidney and pancreas. ${ }^{19}$ GGT takes part in protein metabolism in the body by being involved in the metabolism of glutathione. It can be clinically applied to the diagnosis and prognosis of malignant tumors, renal diseases, cardiovascular diseases and metabolic syndromes. ${ }^{20,22-24}$ Serum GGT is mainly derived from the liver, primarily distributed in the liver cytoplasm and intrahepatic bile duct epithelium, and excreted by the biliary tract. ${ }^{25}$ When biliary obstruction occurs, GGT secreted by biliary epithelial cells and hepatic cells increases; meanwhile, poor bile excretion causes GGT to be absorbed into the bloodstream, leading to the abnormal increase in serum GGT level. Therefore, GGT can clinically be used in the differential diagnosis of biliary obstruction and is able to reflect the degree of biliary obstruction.

We introduced CA19-9/GGT as a novel indicator, which has not been reported before, so as to reduce the influence of biliary obstruction on CA19-9 levels. Although there is a significant correlation between CA19-9 and the diagnosis, prognosis and recurrence of pancreatic cancer, the synthesis of CA19-9 is not unique to pancreatic cancer cells; it may also be synthesized in the normal human pancreas, bile duct, stomach, colon and other epithelial cells. Therefore, an abnormal increase in CA19-9 level can also occur in patients with biliary obstruction, and this increase in CA19-9 can reach more than $20 \%$ in benign biliary obstructive diseases. Pancreatic head cancer often causes biliary obstruction owing to its anatomic location. In our study, the number of patients 
Table 3 Univariate Analysis of Risk Factors for PHC Recurrence

\begin{tabular}{|c|c|c|c|c|c|}
\hline Variables & $\mathbf{N}$ & $\begin{array}{l}\text { I-year } \\
\text { OS (\%) }\end{array}$ & $\begin{array}{l}\text { 3-year } \\
\text { OS (\%) }\end{array}$ & $\chi^{2}$ & $P$ \\
\hline Gender & & & & 1.421 & 0.233 \\
\hline Male & 172 & 53.3 & 21.9 & & \\
\hline Female & 167 & 58.9 & 24.8 & & \\
\hline Age (years) & & & & 2.282 & 0.131 \\
\hline$\leq 60$ & 133 & 60.0 & 25.0 & & \\
\hline$>60$ & 206 & 53.3 & 22.0 & & \\
\hline Diabetes & & & & 3.122 & 0.077 \\
\hline Yes & 117 & 50.3 & 17.6 & & \\
\hline No & 222 & 59.1 & 26.5 & & \\
\hline PBD & & & & 1.848 & 0.174 \\
\hline Yes & 56 & 56.2 & 32.8 & & \\
\hline No & 283 & 56.0 & 21.6 & & \\
\hline $\begin{array}{l}\text { Neoadjuvant } \\
\text { chemotherapy }\end{array}$ & & & & 2.208 & 0.137 \\
\hline Yes & 20 & 35.0 & 20.0 & & \\
\hline No & 319 & 57.4 & 23.3 & & \\
\hline TB $(\mu \mathrm{mol} / \mathrm{L})$ & & & & 1.300 & 0.254 \\
\hline$\leq 21$ & 160 & 52.3 & 20.7 & & \\
\hline$>21$ & 179 & 59.2 & 25.5 & & \\
\hline GGT (U/L) & & & & 0.097 & 0.756 \\
\hline$\leq 45$ & 139 & 54.1 & 26.9 & & \\
\hline$>45$ & 200 & 57.3 & 21.4 & & \\
\hline CAI9-9 (U/mL) & & & & 4.997 & 0.025 \\
\hline$\leq 37$ & 70 & 61.1 & 34.7 & & \\
\hline$>37$ & 269 & 54.6 & 20.4 & & \\
\hline CAI9-9/GGT & & & & $|6.07|$ & 0.000 \\
\hline$\leq 2.07$ & 179 & 68.2 & 28.2 & & \\
\hline$>2.07$ & 160 & 42.2 & 18.3 & & \\
\hline Operative time (h) & & & & 7.751 & 0.005 \\
\hline$\leq 8$ & 111 & 73.0 & 30.7 & & \\
\hline$>8$ & 228 & 47.4 & 19.3 & & \\
\hline Intraoperative & & & & 9.418 & 0.002 \\
\hline blood loss (mL) & & & & & \\
\hline$\leq 800$ & 274 & 60.1 & 26.2 & & \\
\hline$>800$ & 65 & 39.1 & 10.3 & & \\
\hline Blood transfusion & & & & 16.757 & 0.000 \\
\hline Yes & 120 & 37.0 & 15.8 & & \\
\hline No & 219 & 66.4 & 27.3 & & \\
\hline $\begin{array}{l}\text { Degree of } \\
\text { differentiation }\end{array}$ & & & & 6.407 & 0.011 \\
\hline Poor & 87 & 40.8 & 18.3 & & \\
\hline Moderate-high & 252 & 61.3 & 24.8 & & \\
\hline Tumor size $(\mathrm{cm})$ & & & & 6.646 & 0.010 \\
\hline
\end{tabular}

(Continued)
Table 3 (Continued).

\begin{tabular}{|c|c|c|c|c|c|}
\hline Variables & $\mathbf{N}$ & $\begin{array}{l}\text { I-year } \\
\text { OS (\%) }\end{array}$ & $\begin{array}{l}\text { 3-year } \\
\text { OS (\%) }\end{array}$ & $\chi^{2}$ & $P$ \\
\hline$\leq 4$ & 242 & 61.0 & 25.6 & & \\
\hline$>4$ & 97 & 43.7 & 18.4 & & \\
\hline $\mathrm{LN}$ metastasis & & & & 42.160 & 0.000 \\
\hline Yes & 222 & 45.9 & 13.2 & & \\
\hline No & 117 & 75.5 & 42.1 & & \\
\hline $\begin{array}{l}\text { Portal system } \\
\text { invasion }\end{array}$ & & & & 16.234 & 0.000 \\
\hline Yes & 122 & 38.4 & 17.7 & & \\
\hline No & 217 & 65.6 & 26.4 & & \\
\hline Resection margin & & & & 3.612 & 0.057 \\
\hline RO & 314 & 58.0 & 24.1 & & \\
\hline RI & 25 & 32.0 & 16.0 & & \\
\hline $\begin{array}{l}\text { Postoperative } \\
\text { complications }\end{array}$ & & & & 0.593 & 0.441 \\
\hline Yes & 95 & 59.7 & 23.6 & & \\
\hline No & 244 & 54.6 & 22.6 & & \\
\hline $\begin{array}{l}\text { Postoperative } \\
\text { chemotherapy }\end{array}$ & & & & 0.018 & 0.893 \\
\hline Yes & 191 & 57.2 & 21.2 & & \\
\hline No & 148 & 54.6 & 25.2 & & \\
\hline $\begin{array}{l}\text { Chemotheraputic } \\
\text { cycles }\end{array}$ & & & & 0.082 & 0.775 \\
\hline$\leq 2$ & 211 & 55.5 & 22.6 & & \\
\hline$>2$ & 128 & 56.9 & 23.9 & & \\
\hline
\end{tabular}

Abbreviations: OS, overall survival; $\mathrm{PBD}$, preoperative biliary drainage; TB, total bilirubin; GGT, $\gamma$-glutamyltransferase; CA19-9, carbohydrate antigen 19-9; LN, lymph node; $R$, resection margin.

with biliary obstruction caused by pancreatic head cancer resulting in abnormally elevated bilirubin was $52.8 \%$. In clinical practice, it is often observed that after dredging the

Table 4 Multivariate Analysis of Independent Risk Factors for PHC Recurrence

\begin{tabular}{|l|c|c|c|}
\hline Variables & RR & $\mathbf{9 5 \%} \mathbf{~ C l}$ & $\boldsymbol{P}$ \\
\hline CA19-9 & 0.728 & $0.639-1.367$ & 0.728 \\
CA19-9/GGT & 1.397 & $1.054-1.852$ & 0.020 \\
Operative time & 1.197 & $0.873-1.641$ & 0.264 \\
Intraoperative blood loss & 1.028 & $0.670-1.578$ & 0.899 \\
Blood transfusion & 0.791 & $0.55 \mathrm{I}-1.135$ & 0.203 \\
Degree of differentiation & 1.312 & $0.986-1.746$ & 0.062 \\
Tumor size & $1.28 \mathrm{I}$ & $0.964-1.702$ & 0.088 \\
LN metastasis & 2.325 & $1.7 \mathrm{II}-3.160$ & 0.000 \\
Portal system invasion & $1.56 \mathrm{I}$ & $\mathrm{I} .167-2.086$ & 0.003 \\
\hline
\end{tabular}

Abbreviations: CAI9-9, carbohydrate antigen 19-9; GGT, $\gamma$-glutamyltransferase; LN, lymph node. 
Table 5 Univariate Analysis of Long-Term Survival in Patients with PHC

\begin{tabular}{|c|c|c|c|c|c|}
\hline Variables & $\mathbf{N}$ & $\begin{array}{l}\text { I-year } \\
\text { OS (\%) }\end{array}$ & $\begin{array}{l}\text { 3-year } \\
\text { OS (\%) }\end{array}$ & $\chi^{2}$ & $P$ \\
\hline Gender & & & & 2.024 & 0.155 \\
\hline Male & 172 & 68.8 & 22.7 & & \\
\hline Female & 167 & 68.4 & 24.1 & & \\
\hline Age (years) & & & & 1.600 & 0.206 \\
\hline$\leq 60$ & 133 & 71.0 & 24.9 & & \\
\hline$>60$ & 206 & 67.0 & 21.7 & & \\
\hline Diabetes & & & & 3.053 & 0.081 \\
\hline Yes & 117 & 61.4 & 19.9 & & \\
\hline No & 222 & 72.4 & 25.0 & & \\
\hline PBD & & & & 1.012 & 0.314 \\
\hline Yes & 56 & 68.8 & 30.8 & & \\
\hline No & 283 & 68.5 & 22.1 & & \\
\hline $\begin{array}{l}\text { Neoadjuvant } \\
\text { chemotherapy }\end{array}$ & & & & 1.983 & 0.159 \\
\hline Yes & 20 & 45.0 & 20.0 & & \\
\hline No & 319 & 70.1 & 23.5 & & \\
\hline TB $(\mu \mathrm{mol} / \mathrm{L})$ & & & & 1.762 & 0.184 \\
\hline$\leq 21$ & 160 & 67.6 & 20.2 & & \\
\hline$>21$ & 179 & 69.5 & 26.2 & & \\
\hline GGT (U/L) & & & & 0.074 & 0.786 \\
\hline$\leq 45$ & 139 & 70.1 & 26.7 & & \\
\hline$>45$ & 200 & 67.7 & 21.6 & & \\
\hline CAI9-9 (U/mL) & & & & 5.048 & 0.025 \\
\hline$\leq 37$ & 70 & 79.6 & 33.5 & & \\
\hline$>37$ & 269 & 65.8 & 20.8 & & \\
\hline CAI9-9/GGT & & & & 20.612 & 0.000 \\
\hline$\leq 2.07$ & 179 & 79.1 & 29.1 & & \\
\hline$>2.07$ & 160 & 56.7 & 17.2 & & \\
\hline Operative time (h) & & & & 8.114 & 0.004 \\
\hline$\leq 8$ & 111 & 82.9 & 31.2 & & \\
\hline$>8$ & 228 & 61.4 & 19.4 & & \\
\hline Intraoperative & & & & 10.330 & 0.001 \\
\hline blood loss (mL) & & & & & \\
\hline$\leq 800$ & 274 & 73.6 & 26.4 & & \\
\hline$>800$ & 65 & 47.7 & 9.7 & & \\
\hline Blood transfusion & & & & |7.97| & 0.000 \\
\hline Yes & 120 & 50.9 & 15.4 & & \\
\hline No & 219 & 78.2 & 27.8 & & \\
\hline $\begin{array}{l}\text { Degree of } \\
\text { differentiation }\end{array}$ & & & & 6.332 & 0.012 \\
\hline Poor & 87 & 52.4 & 17.3 & & \\
\hline Moderate-high & 252 & 74.2 & 25.4 & & \\
\hline
\end{tabular}

(Continued)
Table 5 (Continued).

\begin{tabular}{|c|c|c|c|c|c|}
\hline Variables & $\mathbf{N}$ & $\begin{array}{l}\text { I-year } \\
\text { OS (\%) }\end{array}$ & $\begin{array}{l}\text { 3-year } \\
\text { OS (\%) }\end{array}$ & $\chi^{2}$ & $P$ \\
\hline $\begin{array}{l}\text { Tumor size }(\mathrm{cm}) \\
\quad \leq 4 \\
>4\end{array}$ & $\begin{array}{c}242 \\
97\end{array}$ & $\begin{array}{l}73.1 \\
57.7\end{array}$ & $\begin{array}{l}26.1 \\
16.5\end{array}$ & 6.717 & 0.010 \\
\hline $\begin{array}{l}\text { LN metastasis } \\
\text { Yes } \\
\text { No }\end{array}$ & $\begin{array}{l}222 \\
117\end{array}$ & $\begin{array}{l}61.5 \\
81.9\end{array}$ & $\begin{array}{l}13.1 \\
42.8\end{array}$ & 43.748 & 0.000 \\
\hline $\begin{array}{l}\text { Portal system } \\
\text { invasion } \\
\text { Yes } \\
\text { No }\end{array}$ & $\begin{array}{l}122 \\
217\end{array}$ & $\begin{array}{l}49.8 \\
78.7\end{array}$ & $\begin{array}{l}16.7 \\
27.0\end{array}$ & 19.010 & 0.000 \\
\hline $\begin{array}{l}\text { Resection margin } \\
\text { R0 } \\
\text { RI }\end{array}$ & $\begin{array}{c}314 \\
25\end{array}$ & $\begin{array}{l}69.0 \\
64.0\end{array}$ & $\begin{array}{l}24.4 \\
16.0\end{array}$ & 4.128 & 0.042 \\
\hline $\begin{array}{l}\text { Postoperative } \\
\text { complication } \\
\text { Yes } \\
\text { No }\end{array}$ & $\begin{array}{c}95 \\
244\end{array}$ & $\begin{array}{l}72.5 \\
67.0\end{array}$ & $\begin{array}{l}22.9 \\
23.3\end{array}$ & 0.003 & 0.954 \\
\hline $\begin{array}{l}\text { Postoperative } \\
\text { chemotherapy } \\
\text { Yes } \\
\text { No }\end{array}$ & $\begin{array}{l}191 \\
148\end{array}$ & $\begin{array}{l}68.6 \\
68.5\end{array}$ & $\begin{array}{l}21.5 \\
24.6\end{array}$ & 0.343 & 0.558 \\
\hline $\begin{array}{l}\text { Chemotheraputic } \\
\text { cycles } \\
\leq 2 \\
>2\end{array}$ & $\begin{array}{l}211 \\
128\end{array}$ & $\begin{array}{l}68.6 \\
68.6\end{array}$ & $\begin{array}{l}23.6 \\
25.2\end{array}$ & 0.069 & 0.793 \\
\hline
\end{tabular}

Abbreviations: OS, overall survival; PBD, preoperative biliary drainage; TB, total bilirubin; GGT, $\gamma$-glutamyltransferase; CA19-9, carbohydrate antigen 19-9; LN, lymph node; $R$, resection margin.

Table 6 Multivariate Analysis of Long-Term Survival in Patients with PHC

\begin{tabular}{|l|c|c|c|}
\hline Variables & RR & 95\% CI & $P$ \\
\hline CAI9-9 & 0.887 & $0.599-1.314$ & 0.550 \\
CAI9-9/GGT & 1.526 & $1.143-2.038$ & 0.004 \\
Operative time & 1.207 & $0.878-1.659$ & 0.248 \\
Intraoperative blood loss & 1.070 & $0.698-1.64 I$ & 0.756 \\
Blood transfusion & 0.792 & $0.549-1.140$ & 0.209 \\
Degree of differentiation & 1.250 & $0.938-1.667$ & 0.128 \\
Tumor size & 1.273 & $0.953-1.701$ & 0.102 \\
LN metastasis & 2.389 & $1.753-3.256$ & 0.000 \\
Portal system invasion & 1.621 & $1.214-2.166$ & 0.001 \\
Resection margin & 1.053 & $0.649-1.709$ & 0.834 \\
\hline
\end{tabular}

Abbreviations: CA19-9, carbohydrate antigen 19-9; GGT, $\gamma$-glutamyltransferase; LN, lymph node. 
biliary tract during treatment to reduce jaundice, the CA19-9 level of patients is greatly reduced even without surgery. Therefore, it is impossible to accurately judge the prognosis of patients based on CA19-9 alone, and our data also showed that CA19-9 was not an independent risk factor affecting the long-term prognosis of patients with PHC.

At present, there are no better preoperative indicators than CA19-9 to judge the long-term prognosis of patients with pancreatic head cancer. Therefore, we hope to correct CA19-9 through a new indicator, so that it can better guide and judge prognosis. In addition, the abnormal increase in CA19-9 is mainly related to biliary obstruction, and at present, the most sensitive indicator of biliary obstruction is GGT. Therefore, we have tried to eliminate the effect of biliary obstruction on CA19-9 by using a mathematical model, and the simplest one is the ratio between the two. The effect of biliary obstruction on CA19-9 can be eliminated by abnormally high GGT in the case of biliary obstruction, which can improve the ability of CA19-9 to judge the prognosis. Our study also confirmed that CA19-9/GGT was an independent risk factor for postoperative tumor recurrence and long-term survival: the lower the CA19-9/GGT level, the better the long-term prognosis. In addition, our research indicated that there was a correlation between CA19-9/ GGT and lymph-node metastasis: the higher CA19-9/GGT level, the higher the rate of lymph-node metastasis. However, there was no correlation between CA19-9/GGT and tumor size or vessel invasion. Given that lymph-node metastasis had been proven to be an independent risk factor for postoperative long-term survival in patients with $\mathrm{PHC}$, we assumed that CA19-9/GGT, similarly to lymph-node metastasis, reflected the aggressiveness and metastasis of the tumor to some degree, but had no association with the local enlargement or direct invasion.

Moreover, our study also indicated that portal system invasion was an independent risk factor for the long-term prognosis of $\mathrm{PHC}$, which corresponded with the results of relevant studies worldwide. ${ }^{26,27}$ Ramacciato et $\mathrm{al}^{28}$ reviewed the data of 406 patients who underwent pancreatic carcinoma surgery in eight pancreatic surgery centers in Italy. Multivariate analysis confirmed that portal system invasion was an independent risk factor for poor prognosis in patients with pancreatic carcinoma. The median survival time and 5-year survival rate among patients with portal system invasion were significantly worse than those without it (20 vs 33 months, $15.5 \%$ vs $31.7 \%$ ). We attributed this to the higher tendency for hematogenous metastasis among tumors with portal vein invasion.

In terms of the limitations of our study, first, it was a single-center retrospective study. Second, we cannot ascertain the proportional relationship between the elevated CA19-9 and GGT, nor can we confirm whether CA19-9 will decrease with GGT proportionately after the biliary obstruction has been cleared. But, according to the current research, CA19-9/GGT may function better than CA19-9 in predicting postoperative tumor recurrence and longterm survival in patients with PHC. An exact proportional relationship between CA19-9 and GGT calculated by a mathematical model may be accessible in correcting CA19-9 in the near future, enabling clinicians to make better treatment decisions and to detect postoperative tumor recurrence.

\section{Conclusion}

In summary, CA19-9/GGT, which can be acquired easily before an operation, is more valuable in predicting the postoperative recurrence of $\mathrm{PHC}$ and evaluating the longterm prognosis of patients compared to CA19-9 alone, so that clinicians can make better treatment decisions and optimize the postoperative treatment plan based on the preoperative CA19-9/GGT.

\section{Data Sharing Statement}

The data used and analyzed in this study are included in the article or are available from the corresponding and first authors on reasonable request.

\section{Ethics Approval}

The study was conducted in accordance with the Declaration of Helsinki (as revised in 2013) and was approved by the Ethics Committee of Beijing Chaoyang Hospital (No. 2020-D.-309-2). The need for participants' informed consent was exempted because of the retrospective study design, and the study design was approved by the appropriate ethics review board.

\section{Consent for Publication}

Not applicable.

\section{Author Contributions}

Contributions: i) conception and design: Jing Wang, Shaocheng Lyu; ii) administrative support: Qiang He, Ren Lang; iii) provision of study materials or patients: Shaocheng Lyu, Ren Lang; iv) collection and assembly of data: 
Meng-xiu Huang, Han-xuan Wang; v) data analysis and interpretation: Shao-cheng Lyu, Jing Wang, Lin Zhou; vi) manuscript writing: all authors; vii) final approval of manuscript: all authors. All authors made substantial contributions to conception and design, acquisition of data, or analysis and interpretation of data; took part in drafting the article or revising it critically for important intellectual content; agreed to submit to the current journal; gave final approval of the version to be published; and agree to be accountable for all aspects of the work.

\section{Funding}

This study was supported by Beijing Municipal Science \& Technology Commission, PR China (grant no. Z181100001718164); and Capital's Funds for Health Improvement and Research, Beijing, PR China (CFH 2020-1-2036).

\section{Disclosure}

The authors declare no conflicts of interest.

\section{References}

1. Bray F, Ferlay J, Soerjomataram I, et al. Global cancer statistics 2018: GLOBOCAN estimates of incidence and mortality worldwide for 36 cancers in 185 countries. CA Cancer J Clin. 2018;68 (6):394-424. doi:10.3322/caac. 21492

2. Siegel RL, Miller KD, Jemal A. Cancer statistics, 2018. CA Cancer J Clin. 2018;68(1):7-30. doi:10.3322/caac.21442

3. Zhu H, Li T, Du Y, et al. Pancreatic cancer: challenges and opportunities. BMC Med. 2018;16(1):214. doi:10.1186/s12916-0181215-3

4. Bergquist JR, Puig CA, Shubert CR, et al. Carbohydrate Antigen 19-9 elevation in anatomically resectable, early stage pancreatic cancer is independently associated with decreased overall survival and an indication for neoadjuvant therapy: a National Cancer Database Study. J Am Coll Surg. 2016;223(1):52-65. doi:10.1016/j. jamcollsurg.2016.02.009

5. Boeck S, Stieber P, Holdenrieder S, et al. Prognostic and therapeutic significance of carbohydrate antigen 19-9 as tumor marker in patients with pancreatic cancer. Oncology. 2006;70(4):255-264.

6. Lee SP, Sung IK, Kim JH, et al. Usefulness of carbohydrate antigen 19-9 test in healthy people and necessity of medical follow-up in individuals with elevated carbohydrate antigen 19-9 level. Korean $J$ Fam Med. 2019;40(5):314-322. doi:10.4082/kjfm.18.0057

7. Zhang GM, Bai SM, Zhang GM, et al. Reference intervals of carbohydrate antigen 19-9 in the apparently healthy adult population. J Clin Lab Anal. 2018;32(5):e22380. doi:10.1002/jcla.22380

8. Lin MS, Huang JX, Yu H. Elevated serum level of carbohydrate antigen 19-9 in benign biliary stricture diseases can reduce its value as a tumor marker. Int J Clin Exp Med. 2014;7(3):744-750.

9. Marrelli D, Caruso S, Pedrazzani C, et al. CA19-9 serum levels in obstructive jaundice: clinical value in benign and malignant conditions. Am J Surg. 2009;198(3):333-339. doi:10.1016/j. amjsurg.2008.12.031

10. Whitfield JB. Gamma glutamyl transferase. Crit Rev Clin Lab Sci. 2001;38:263-355.
11. Xiao Y, Yang H, Lu J, et al. Serum gamma-glutamyltransferase and the overall survival of metastatic pancreatic cancer. BMC Cancer. 2019;19(1):1020. doi:10.1186/s12885-019-6250-8

12. Hlavsa J, Cecka F, Zaruba $P$, et al. Tumor grade as significant prognostic factor in pancreatic cancer: validation of a novel TNMG staging system. Neoplasma. 2018;65(4):637-643. doi:10.4149/ neo_2018_171012N650

13. Barugola G, Partelli S, Crippa S, et al. Time trends in the treatment and prognosis of resectable pancreatic cancer in a large tertiary referral centre. HPB (Oxford). 2013;15(12):958-964. doi:10.1111/hpb.12073

14. O'Brien DP, Sandanayake NS, Jenkinson C, et al. Serum CA19-9 is significantly upregulated up to 2 years before diagnosis with pancreatic cancer: implications for early disease detection. Clin Cancer Res. 2015;21(3):622-631. doi:10.1158/1078-0432.CCR-14-0365

15. Sugiura T, Uesaka K, Kanemoto $H$, et al. Serum CA19-9 is a significant predictor among preoperative parameters for early recurrence after resection of pancreatic adenocarcinoma. $J$ Gastrointest Surg. 2012;16(5):977-985. doi:10.1007/s11605-012-1859-9

16. Laurent L, Sefrioui D, Bignon AL, et al. CA19.9 decrease $>15 \%$ is a predictor of favourable outcome in patients treated for advanced pancreatic carcinoma: analysis of two independent cohorts. $H P B$ (Oxford). 2019;21(5):582-588. doi:10.1016/j.hpb.2018.09.006

17. Rieser CJ, Zenati M, Hamad A, et al. CA19-9 on postoperative surveillance in pancreatic ductal adenocarcinoma: predicting recurrence and changing prognosis over time. Ann Surg Oncol. 2018;25 (12):3483-3491. doi:10.1245/s10434-018-6521-7

18. Mann DV, Edwards R, Ho S, et al. Elevated tumour marker CA19-9: clinical interpretation and influence of obstructive jaundice. Eur J Surg Oncol. 2000;26(5):474-479. doi:10.1053/ejso.1999.0925

19. Hanigan MH. Gamma-glutamyl transpeptidase: redox regulation and drug resistance. Adv Cancer Res. 2014;122:103-141.

20. Fu SJ, Zhao Q, Ji F, et al. Elevated preoperative serum gamma-glutamyltranspeptidase predicts poor prognosis for hepatocellular carcinoma after liver transplantation. Sci Rep. 2016;6:28835. doi:10.1038/srep28835

21. Le N, Sund M, Vinci A. GEMS collaborating group of Pancreas 2000. Prognostic and predictive markers in pancreatic adenocarcinoma. Dig Liver Dis. 2016;48(3):223-230. doi:10.1016/j.dld.2015.11.001

22. Kunutsor SK, Laukkanen JA. Gamma-glutamyltransferase and risk of chronic kidney disease:Aprospective cohort study. Clin Chim Acta. 2017;473:39-44. doi:10.1016/j.cca.2017.08.014

23. Dalos D, Binder C, Duca F, et al. Serum levels of gamma-glutamyltransferase predict outcome in heart failure with preserved ejection fraction. Sci Rep. 2019;9(1):18541. doi:10.1038/s41598019-55116-8

24. Coku V, Shkembi X. Serum Gamma-glutamyltransferase and Obesity: is there a Link? Med Arch. 2018;72(2):112-115. doi:10.5455/medarh.2017.72.112-115

25. Mei Y, Chen L, Zeng PF, et al. Combination of serum gamma-glutamyltransferase and alkaline phosphatase in predicting the diagnosis of asymptomatic choledocholithiasis secondary to cholecystolithiasis. World J Clin Cases. 2019;7(2):137-144. doi:10.12998/wjcc.v7.i2.137

26. Wang J, Lyu SC, Zhou L, et al. Prognostic analysis of pancreatic carcinoma with portal system invasion following curative resection. Gland Surg. 2021;10(1):35-49. doi:10.21037/gs-20-495

27. Kim M, Kang TW, Cha DI, et al. Prediction and clinical implications of portal vein/superior mesenteric vein invasion in patients with resected pancreatic head cancer: the significance of preoperative CT parameters. Clin Radiol. 2018;73(6):564-573. doi:10.1016/j. crad.2018.01.016

28. Ramacciato G, Nigri G, Petrucciani N, et al. Pancreatectomy with mesenteric and portal vein resection for borderline resectable pancreatic cancer: multicenter study of 406 patients. Ann Surg Oncol. 2016;23(6):2028-2037. doi:10.1245/s10434-016-5123-5 


\section{Publish your work in this journal}

Cancer Management and Research is an international, peer-reviewed open access journal focusing on cancer research and the optimal use of preventative and integrated treatment interventions to achieve improved outcomes, enhanced survival and quality of life for the cancer patient.
The manuscript management system is completely online and includes a very quick and fair peer-review system, which is all easy to use. Visit http://www.dovepress.com/testimonials.php to read real quotes from published authors.

Submit your manuscript here: https://www.dovepress.com/cancer-management-and-research-journal 